\title{
Prevalence of Low Birth Weight in Mbuji-Mayi City, Democratic Republic of Congo
}

\author{
Kanyiki Katala Moise1* ${ }^{*}$ Banza Ndala Deca Blood1, Ciamala Mukendi Paul2, \\ Mukendi Mukendi Jean Réne², Kanyeba Mulumba Odette1, Kabulo Kasongo Benjamin'3, \\ Kabumba Kabumba François ${ }^{4}$, Kabamba Nzaji Michel $^{5}$
}

\footnotetext{
${ }^{1}$ Higher Institute of Medical Techniques of Mbuji-Mayi, Community Health Section of Epidemiology Option, Mbuji-Mayi, Democratic Republic of Congo

${ }^{2}$ Higher Institute of Medical Techniques of Mbuji-Mayi, Nursing Section, Teaching and Administration Option in Nursing, Mbuji-Mayi, Democratic Republic of Congo

${ }^{3}$ Official University of Mbujimayi, Faculty of Medicine, Department of Pediatrics, Mbuji-Mayi, Democratic Republic of Congo ${ }^{4}$ Official University of Mbujimayi, Faculty of Medicine, Department of Surgery, Mbuji-Mayi, Democratic Republic of Congo ${ }^{5}$ Faculty of Medicine, Department of Public Health, University of Kamina, Kamina, Democratic Republic of Congo Email: *kanyikikatala@gmail.com
}

How to cite this paper: Moise, K.K., Blood, B.N.D., Paul, C.M., Réne, M.M.J., Odette, K.M., Benjamin, K.K., François, K.K. and Michel, K.N. (2017) Prevalence of Low Birth Weight in Mbuji-Mayi City, Democratic Republic of Congo. Open Access Library Journal, 4: e3474.

https://doi.org/10.4236/oalib.1103474

Received: March 2, 2017

Accepted: March 27, 2017

Published: March 30, 2017

Copyright $\odot 2017$ by authors and Open Access Library Inc.

This work is licensed under the Creative Commons Attribution International License (CC BY 4.0).

http://creativecommons.org/licenses/by/4.0/

\begin{abstract}
Low birth weight is a major public health problem, both in developed countries and developing countries, by its magnitude and its strong association with morbidity and mortality. The aim in this study was to determine the prevalence of low birth weight in Mbuji-Mayi. This is a descriptive study conducted in the city of Mbuji-Mayi in three health zones targeted by the study which DUILU, Dibindi and KANSELE among natal women and their newborns respectively registered for the period of one month, from 1 June to 30 June 2015. Data were collected in an integrated way. The following observations were made: in the study period, 1266 women were interviewed. After analysis: the prevalence of low weight was $14.3 \%$; gestational age at birth superior to 36 SA represented $89.9 \%$ and $50.6 \%$ of newborns were female.
\end{abstract}

\section{Subject Areas}

Public Health

\section{Keywords}

Prevalence, Low Weight, Mbuji-Mayi

\section{Introduction}

The low birth weight (LBW) is defined by the World Health Organization as a birth weight less than $2500 \mathrm{~g}$ at [1]. The United Nations Children's Fund esti- 
mates that nearly 20 million children are born with low birth weight each year worldwide, about $15 \%$ of all live births. Over $95 \%$ of cases occur in developing countries [2].

It is a major public health problem, both in developed countries and developing countries, by its magnitude and its strong association with morbidity and mortality. The two main causes of underweight at birth are premature birth and intrauterine growth restriction (IUGR) or a combination of both [3].

In developing countries where malnutrition is common, about $80 \%$ of underweight are due to growth retardation intrauterine largely due to maternal malnutrition. In contrast, in industrialized countries, preterm birth is the leading cause of FPN. About two thirds of low birth weights are also premature [4].

The resulting complications are varied, ranging from metabolic disorders to neurological and sensory disorders, sometimes irreversible [5]. The risk of death is 20 times higher in infants of low weight than those whose weight is greater than $2500 \mathrm{~g}$. The more the birth weight, the smaller the risk of death increases. These infants are a vulnerable group because the problems they pose are also linked to requirements inherent in their care. Low birth weight is a leading cause of neonatal mortality and morbidity [2].

Africa, despite the efforts, still ranks the second high rates of low birth weight. Incidence of low birth weight (LBW) is still above the standard set by the WHO which is less than $10 \%$. Northern Africa seems the most affected, with $15.3 \%$ in 2000 . West Africa, including in Senegal, a study conducted by WHO, revealed an $18 \%$ rate in 2000. In Central Africa studies by WHO showed an incidence of $14 \%$ in Gabon, $14 \%$ in the CAR in 2000, 17\% for Chad in 1997 and Cameroon in 1998 11\% [6].

In the Democratic Republic of Congo, in a study conducted in 2012 on the factors associated with low birth weight, this category of children represented $8.7 \%$ over the whole of the country [7]. The results obtained by Milobyo Maniema during the period 2003-2004 showed that the proportion of low birth weight is not altogether different from that of other developing countries and remains high at $27 \%$ and $16.4 \%$ in Kipaka Kama, both areas of Maniema province [8]. The results of the study conducted in semi-rural Kamina who were "risk factors for low birth weight" show that 69 cases of newborn LBW deliveries are recorded on 483 or $14.3 \%$ [9].

In the Kasai Oriental province in general and the city of Mbuji- Mayi in particular, our research community is not spared by this scourge. Because by simple observation, we cannot doubt the precarious state in which women live their pregnancy.

The present study aims to determine the prevalence of newborns of low birth weight received in maternity hospitals in the city of Mbuji-Mayi to contribute to achieving the objective No. 4 of the Millennium Development Goals, namely two-thirds reduction in mortality of children under 5 years between 1990 and 2015 [10].

\section{Material and Methods}

We conducted a descriptive study in three health areas of the Health District 
Mbuji-Mayi represent the administrative entity of the city of Mbuji-Mayi (Diulu, KANSELE and Dibindi).

We used the semi-structured interview technical face to face. This study focuses on a sample of 1266 women surveyed during one month, from 1 June to 30 June 2015. The following variables were selected for this study: Birth weight, sex of child, gestational age, maternal age, maternal education, marital status, parity, gravidity and attendance of antenatal care.

Were included in this study, all the women who gave birth a newborn less than $4500 \mathrm{~g}$ weight during the period fixed and in health areas targeted by this study; being able to speak French or Ciluba, the language in which the surveys were conducted freely and accepting an enlightened way to participate in the study. As an exclusion criterion, any woman has given birth to a newborn macrosomic (greater than $4500 \mathrm{~kg}$ weight) and does not meet the criteria of inclusion.

The collected data were coded, entered, processed and analyzed using SPSS 20. Descriptive analysis was performed using the proportions calculations.

This study was approved by related ethics committee besides and mothers sign informed consent and have a whole understanding of this study. Our study had no binding character. Any information collected from mothers has been and will remain confidential. Similarly, the names of participants will remain confidential and will not be mentioned in the presentation of results or associated to results in any way whatsoever.

\section{Results}

It appears from this table that the majority of women in our study were older than 20 years is $75.6 \% ; 22.1 \%$ of them were of the lower level of study and $77.9 \%$ a higher level of education. Note that $92.2 \%$ of women in our series were married and $78.0 \%$ were multigravidae and $23.5 \%$ of first pregnancies. In connection with the parity, $78.0 \%$ of mothers were multiparous and $22.0 \%$ of first-time. The majority of mothers in this study followed the prenatal consultation (Tables 1-4).

Table 1. Distribution by birth weight.

\begin{tabular}{ccc}
\hline Weight newborn & Effective & Percentage \\
\hline Low weight (lower to $2500 \mathrm{~g})$ & 183 & $14.5 \%$ \\
normal weight $(2500 \mathrm{~g}$ and more) & 1083 & $85.5 \%$ \\
Total & 1266 & $100 \%$ \\
\hline
\end{tabular}

Table 1 shows that the prevalence of children born with low weight was $14.5 \%$.

Table 2. Distribution of cases according to the child's sex.

\begin{tabular}{ccc}
\hline Gender Newborn & Effective & Percentage \\
\hline Male & 625 & $49.4 \%$ \\
Female & 641 & $50.6 \%$ \\
Total & 1266 & $100 \%$ \\
\hline
\end{tabular}

The majority of infants in this study were female or $50.6 \%$ with a sex ratio is $0.97 \mathrm{M} / \mathrm{F}$. 
Table 3. Distribution of cases according to gestational age at birth.

\begin{tabular}{ccc}
\hline Gestational age & Effective & Percentage \\
\hline Lower 36 SA & 132 & $10.4 \%$ \\
Greater than or equal to 36 weeks & 1134 & $89.6 \%$ \\
Total & 1266 & $100 \%$ \\
\hline
\end{tabular}

Gestational age at birth less than 36 weeks is $10.4 \%$ against $89.9 \%$ of children born at term.

Table 4. Breakdown of cases according to the characteristics of mothers.

\begin{tabular}{|c|c|c|}
\hline Characteristics & Effective & Percentage \\
\hline \multicolumn{3}{|l|}{ The age of mothers } \\
\hline$\leq 20$ years & 309 & $24.4 \%$ \\
\hline$>20$ years & 957 & $75.6 \%$ \\
\hline \multicolumn{3}{|l|}{ Civil status } \\
\hline married & 1167 & $92.2 \%$ \\
\hline unmarried & 99 & $7.8 \%$ \\
\hline \multicolumn{3}{|l|}{ Study level } \\
\hline Low level & 280 & $22.1 \%$ \\
\hline A higher level & 986 & $77.9 \%$ \\
\hline \multicolumn{3}{|l|}{ Gravidity } \\
\hline primigravidae & 298 & $23.5 \%$ \\
\hline multigravidae & 968 & $76.5 \%$ \\
\hline \multicolumn{3}{|l|}{ Parity } \\
\hline primiparae & 279 & $22.0 \%$ \\
\hline Multiparous (greater than or equal to 2) & 987 & $78.0 \%$ \\
\hline \multicolumn{3}{|l|}{ Monitoring EIC } \\
\hline Yes & 975 & $77.0 \%$ \\
\hline No & 291 & $23.0 \%$ \\
\hline
\end{tabular}

\section{Discussion}

The high proportion of children underweight at birth in developing countries is seen as an indicator of nutritional status of pregnant women as very important determinant of infant mortality. So one of the objectives of the WHO is to reduce rate underweight children, less than $10 \%$ by the year 2000 [11]. The prevalence of low birth weight in our study was $14.5 \%$. These results are higher than those found by Sandrine E. (2012) over the whole of DR Congo 8.7\% [7]. This prevalence is similar to that of Bwana Kangulu, who found 14.3\% [9]. This prevalence was much lower than Mugisho (2007) $18 \%$, 27\% and $16.4 \%$ to Kipaka Kama found by MILOBYO (2004) [8]. Although higher than the average of developed countries $7 \%$ but this rate is below the average of countries in development $16 \%$ [2].

The proportion of newborns of low weight described in our study was higher than the WHO standard (minus 10\%). Several studies have shown the influence of maternal diet during pregnancy on the weight of newborns [12]. The high 
frequencies in developing countries in this category of children in general and in particular the Eastern Kasai could be explained by the multiplicity of unrecovered risk factors in developed countries. A study of Kusín et al. published in the Lancet in 1992 went further and showed that in a community in which women of reproductive age suffer from chronic energy deficiency as Kasai Oriental, the correction of this deficiency not only causes an increase in weight birth but also influences the growth of these children later [13]. In developing countries where malnutrition is common, about $80 \%$ of underweight are due to intrauterine growth restriction largely due to maternal malnutrition [4].

The majority of the newborns of this study is female (50.6\%). The sex ratio is 0.97 (Table 2). These results corroborate with those of Ntsama E. (2011) found in gynecology and obstetrics and pediatric hospital in Yaounde where he showed that the majority of children series were female, the sex ratio was 0.92 [14]. Lower than that found by Norotiana Rabesandratana, Madagascar 1.2 and 1.4 Aboussad CHU Marakech Morocco [15].

Gestational age at birth (Table 3) less than $36 \mathrm{SA}$ is $10.4 \%$ against $89.9 \%$ of children born at term. From Table 4 that $24.4 \%$ of mothers are aged up to 20 years against $75.6 \%$ of mothers whose age ranges from 21 years to 35 years. These results are consistent with those of Demmouche. These results are consistent with those of Demmouche qui revealed in 2015 that $72.8 \%$ of mothers had an age between 20 and 34 years [16]. Among the 1,266 women surveyed, 280 (22.1\%) of them have a lower level of education and 986 (77.9\%) of them have a higher level of education. The majority of mothers (92.2\%) in our series are married and only (7.8\%) unmarried. Most women in this study are multigravidae 987 women $(78.0 \%)$ and $23.5 \%$ of first pregnancies are. Compared to the parity, $78.0 \%$ of MESRES are multiparous and $22.0 \%$ of first-time. The majority of mothers in this study followed the prenatal consultation.

\section{Conclusion}

Low birth weight is a public health issue that deserves special attention. With the objective of determining the prevalence of low birth weight in the city, we presented the study led to the findings that the prevalence of low birth weight remains above the WHO standard (less than 10\%). The prevalence of this child category was $14.5 \%$. The majority of the newborns of this study is female (50.6\%). The sex ratio was 0.9. Gestational age at birth less than 36 weeks of gestation is $10.4 \% ; 24.4 \%$ of mothers aged less than or equal to 20 years; $22.1 \%$ had a lower level of study; $92.2 \%$ of mothers in our series are married. Most women in this study are multigravidae. $78.0 \%$ of mothers were multiparous. At any time another study proves significant to determine the factors that explain this high frequency in the city of Mbuji-Mayi low birth weight.

\section{References}

[1] WHO (2006) The Partnership for Maternal, New Born and Child Heath. Opportun- 
ities for Africa's Newborn, Geneva.

[2] United Nations Children's Fund and World Health Organization, Low Birthweight: Country, Regional and Global Estimates. UNICEF: New York, 2004.

http://www.unicef.org/publications/index_24840.html

[3] Miaffo Sokeng, L. (2008) Risk Factors and Prognosis of Cases of Low Birth Weight Collected in Gynecology and Obstetrics and Pediatric Hospital in Yaoundé (Cameroon). www.memoireonline.Com/a/fr/cart/add/8220

[4] Pollitt, E., Gorman, K.S., Engle, P.L., Rivera, J.A. and Martorell, R. (1995) Nutrition in Early Life and the Fulfillment of Intellectual Potential. Journal of Nutrition, 125, 1111S-1118S.

[5] Patrick, K., et al. (2007) Obstetric Risk Factors of Small Term Birth Weight in Sahelian Rural. Public Health, 19, 489-497.

[6] Glavce, C., Dragomirescu, L., Valentin G. and Apavaloae, L. (2001) The Evolution of Birth Weights for the Different Socio-Economic Conditions. Review of the Society of Human Biometry and Anthropology, 19, No. 1-2.

[7] Sandrine, E. (2012) Factors Associated with Low Birth Weight, Brussels.

[8] Kyamusugulwa, P.M. (2006) Low Birth Weight in Maniema (Democratic Republic of the Congo). Workbooks and Francophone Research/Health, 16, 103-107.

[9] Bwana Kangulu, I., Umba, K.N., et al. (2014) Risk Factors for Low Weight SemiRuralde Environment Birth Kamina, Democratic Republic of Congo. Pan African Medical Journal, 17, 220. www.ncbi.nlm.nih.gov/pubmed/?term=UmbaEK(auth)

[10] Nation University (2005) OMD Rapport 2005. Nation University, New York. http://www.unicef.org/french/progressforchildren/2006n4/index_indicators.html

[11] World Health Organization (2000) Development of Indicators for Monitoring Progress towards Health for All by the Year 2000.

[12] Piechulek, H. and Mendoza Aldana, J. (1996) Children Underweight at Birth: The Requirements of a Nutritional Surveillance Program. Example: The Rural Area of the Province of the Coast. Cameroon.

[13] Kusín, A. (1992) Energy Supplementation during Pregnancy and Postnatal Growth. The Lancet, 340, 623-626.

[14] Essomba and Tchokoteu, N. (2011) Determinants of Hospital Become Newborn Very Low Birth Weight in Gynecology and Obstetrics and Pediatric Hospital in Yaounde.

[15] Mande, B.G. and Falay, S.D. (2014) Evaluation of the Care to Premature Clinics University of Kisangani. DRC, Atlanta.

[16] Demmouche, A., Benali, A.I., Ghani, A.E., May, H., Beddek, F., Chalal, H. and Rahmani, S. (2015) Etiology of Low Birth Weight at the Maternity Sidi Bel Abbes (West Algeria). Antropo, 33, 103-109. www.didac.ehu.es/antropo 
Submit or recommend next manuscript to OALib Journal and we will provide best service for you:

- Publication frequency: Monthly

- 9 subject areas of science, technology and medicine

- Fair and rigorous peer-review system

- Fast publication process

- Article promotion in various social networking sites (LinkedIn, Facebook, Twitter, etc.)

- Maximum dissemination of your research work

Submit Your Paper Online: Click Here to Submit

Or Contact service@oalib.com 